\title{
On Orenstein's and Meighan's finding of left visual field recognition superiority for bilaterally presented words
}

\author{
WALTER F. McKEEVER \\ Bowling Green State University, Bowling Green, Ohio 49409
}

\begin{abstract}
Orenstein and Meighan failed to control, or in any way monitor, the subjects' point of fixation. Ample evidence attests to the importance of insuring the intended fixation in bilateral presentation studies of half-field word recognition differences. When fixation control is insured, right, not left, visual field superiority obtains. Orenstein and Meighan's experiment offers no evidence against the "lateral dominance" hypothesis regarding visual half-field recognition performance differences.
\end{abstract}

Orenstein and Meighan (1976) reported that words presented bilaterally, relative to the fixation point, were recognized significantly better in the left visual field (LVF) than in the right visual field (RVF). Their experiment was prompted by an earlier one (Ellis \& Shepherd, 1974) which found RVF superiority for both "abstract" and "concrete" words and significantly greater recognition of "concrete" than of "abstract" words within the LVF. Orenstein and Meighan found their LVF superiority to be independent of variations in either "concreteness" or the printed frequencies of the words.

The authors concluded that their results were not compatible with a cerebral dominance model but were compatible with Heron's (1957) well-known directional scanning model. Specifically, they noted, "It is clear that the present results, while in direct contrast to those reported by Ellis and Shepherd (1974), are in accord with the majority of evidence concerning verbal material presented bilaterally (see Paivio, 1971; White, 1969)." They also noted that their results appeared "to contradict those reported by McKeever (1971)" but suggested that the much briefer exposures of the McKeever experiment might have obviated the sequential processing of the stimulus array. It should be noted that the "majority of evidence" the authors cited as in accord with their findings was all conducted prior to 1971 and consistently failed to control or monitor the actual fixation point adopted by subjects.

The finding I wish to take issue with is that of LVF superiority. Whether concrete or abstract words are differentially recognizable in the half-fields is an open question. Specifically, the points I wish to make are: (a) that assurance regarding the subjects' fixation is an essential requirement of such bilateral presentation experiments, and (b) that when such assurance has been secured, the evidence for RVF, not LVF, recognition superiority is rather overwhelming.

Failure to control, or at least monitor, the subjects' fixation constitutes a critical weakness in the Orenstein and Meighan experiment. The naive assumption-characteristic, I regret to say, of nearly the entirety of work on "serial position effects" in recognition of tachistoscopically presented letter arrays for a period of about 50 years-should not be perpetuated in 1976. Strong habits to look to the "beginning" of the letter array undoubtedly exist, as Heron (1957) rightly hypothesized. Subjects free to look where they choose will deviate their fixation from the intended fixation point in accordance with the "payoff matrix" of the experiment, which is typically to simply recognize as many stimuli as possible. When the subject knows that words will appear bilaterally on every trial, the strategy of moving one's fixation to or toward the point corresponding to the beginning (leftmost element) of the array is maximally effective for overall recognition performance, since all words then fall within the RVF. The fact that LVF superiority obtains only under conditions of uncontrolled and/or unmonitored fixation offers strong support for the validity of this explanation. The Orenstein and Meighan study, like that of Hines (1972), provides only more recent evidence than cited by Orenstein and Meighan for the probable operation of this strategy.

When care has been taken to insure the intended fixation, or when the location of the stimulus words is not predictable, so that midfield fixation is maximally effective, RVF superiority clearly obtains. Numerous experiments, utilizing a wide range of exposure times, attest to this central fact. Thus, strong RVF superiority has been found when fixation is controlled by a requirement that subjects report a small digit appearing at the fixation point on all bilateral stimulus trails (Gill \& McKeever, 1974; Hines, 1972, 1975; Klein, Moscovitch, \& Vigna, 1976; Mackavey, Curcio, \& Rosen, 1975; McKeever, 1971; McKeever \& Huling, 1971a, b; and others). When subjects are required to report a digit that "might appear" at fixation (actually appearing $50 \%$ of the time), RVF superiority is just as great as when digits appear on every trial (McKeever, Suberi, 
\& VanDeventer, 1972). Finally, when the subject cannot predict where the words will appear (unilateral and bilateral trials intermixed), strong RVF superiority obtains for both unilateral and bilateral trials without any stimulus appearing at fixation at all (Kerschner \& Gwan-Rong Jeng, 1972; Olson, 1973).

Orenstein and Meighan's conclusion that, as a model for explaining lateral recognition asymmetries, "the concept of cerebral dominance may be only an inappropriate label applied to a group of factors related to sequential aspects of perceptual processing" is unjustified. Their experiment lacked the power to assess the model.

\section{REFERENCES}

Ellis, H. D., \& Shepherd, J. W. Recognition of abstract and concrete words presented in left and right visual fields. Journal of Experimental Psychology, 1974, 103, 1035-1036.

Gill, K. M., \& McKeEver, W. F. Word length, exposure time, and word length/exposure time interaction effects on bilateral word recognitions. Bulletin of the Psychonomic Society, 1974, 4, 173-175.

Heron, W. Perception as a function of retinal locus and attention. American Journal of Psychology, 1957, 70, 38-48.

Hines, D. Bilateral tachistoscopic recognitions of verbal and nonverbal stimuli. Cortex, 1972, 8, 315-322.

HiNes, D. Independent functioning of the two cerebral hemispheres for recognizing bilaterally presented tachistoscopic visual half-field stimuli. Cortex, 1975, 11, 132-143.

Kerschner, J. A., \& Gwan-Rong Jeng, A. Dual functional hemispheric asymmetry in visual perception: Effects of ocular duminance and postexposural processes. Neuropsychologia, 1972, 10, 437-445.
Klein, D., Moscovitch, M., \& Vigna, C. Attentional mechanisms and perceptual asymmetries in tachistoscopic recognition of words and faces. Neuropsychologia, 1976, 14, 55-66.

Mackavey, W., Curcio, F., \& Rosen, J. Tachistoscopic word recognition performance under conditions of simultaneous bilateral presentation. Neuropsychologia, 1975, 13, 27-33.

MCKeEver, W. F. Lateral word recognition effects of unilateral and bilateral presentation, asynchrony of bilateral presentation, and forced order of report. Quarterly Journal of Experimental Psychology, 1971, 23, 410-416.

MCKeever, W. F., \& Huling, M. D. Lateral dominance in tachistoscopic word recognition performances obtained with simultaneous bilateral input. Neuropsychologia, 1971, 9. 15-20. (a)

McKeever, W. F., \& Huling, M. D. Bilateral tachistoscopic word recognition as a function of hemisphere stimulated and interhemispheric transfer time. Neuropsychologia, 1971, 9, 281-288. (b)

McKeever, W. F., Suberi, M., \& VanDeventer, A. D. Fixation control in tachistoscopic studies of laterality effects: Comments and data relevant to Hines' experiment. Cortex, 1972, 8, 473-479.

Olson, M. E. Laterality differences in tachistoscopic word recognition in normal and delayed readers in elementary school. Neuropsychologia, 1973, 11, 343-350.

Orenstein, H. B., \& Meighan, W. B. Recognition of bilaterally presented words varying in concreteness and frequency: Lateral dominance or sequential processing? Bulletin of the Psychonomic Society, 1976, 7, 179-180.

Paivo, A. Imagery and verbal processes. New York: Holt, Rinehart, \& Winston, 1971.

White, M. J. Laterality differences in perception: A review. Psychological Bulletin, 1969, 72, 387-405.

(Received for publication April 7, 1976.) 